\title{
The Journal - A More Rapid Publication Process
}

As Editors of The Journal of Rheumatology we are pleased to inform you that The Journal is offering our traditional excellence in clinical research to the international rheumatology community more rapidly!

Advances in our peer review and editorial production processes have resulted in a shorter time from submission to first decision and from acceptance to publication, despite steadily increasing submissions since 2006.

In 2009 The Journal received about 1500 submissions, of which 1000 were full length manuscripts. As authors, reviewers, board members (Table 1), and staff make better use of our integrated Web based review system, we can shorten our decision turnaround time: for manuscripts that meet requirements for external peer review, the time from submission to review assignment is about 10 days and time to first decision, about 35 days; moreover, if we look at all manuscripts we receive, the average time from submission to first decision is only 21 days.

Every month, thoughtful and insightful feedback to manuscripts is provided by our established and newer reviewers: their contribution enriches the quality of authorship and enhances the insight of fellow reviewers, editorial board members, and readers alike. While not all deserving manuscripts can be accepted, all improve as a result of the review process.

For the $30 \%$ or so full length manuscripts that are accepted, publication now takes less time. First, via our Online First Release program, articles are posted to jrheum.org as edited, formatted and indexed PDFs about 10 weeks after month of acceptance. Second, a month or two later, the article is fully published in our monthly print and online issue.

As for reader experience, Journal content is now easier to discover and more convenient to use. Since our new website jrheum.org launched in 2009, viewers have benefitted from smoother navigation, faster more effective searching, as well as citation tracking and personal alert options. Functional XML format, highly readable table and figure display, and viewing features such as inter-journal hyperlinking help promote higher reader retention. And regardless of subscription status Editorials, Full Release ("open access") articles, and case reports are all freely available.

Our Web viewers vote with their mouse: In a given month they download or view roughly 4000 unique articles over 70,000 times, providing rapid feedback for the Editorial Committee (Figure 1). For example, of articles published in our July issue, interest was highest for
Table 1. The Journal's Editorial Board, January 2011.

Steve Abramson
Jonathan Adachi
Graciela Alarcon
Frank C. Arnett
David A. Bell
Howard A. Bird
Maarten Boers
Earl Bogoch
Kenneth D. Brandt
Barry Bresnihan
Matthew Brown
Gerd R. Burmester
Jeffrey P. Callen
Juan J. Canoso
Christopher Denton
Patrick Dessein
John A. DiBattista
Paul Dieppe
Maxime Dougados
George E. Ehrlich
Hani El-Gabalawy
John Esdaile
David T. Felson
Marcos Ferraz
James E. Fries
Marvin J. Fritzler
Daniel E. Furst
Sherine Gabriel
Charles H. Goldsmith
Rose Goldstein
Miguel Gonzalez-Gay
Bevra Hahn
John G. Hanly
Gillian Hawker
John Highton
Marc C. Hochberg
Gary Hoffman
Graham R.V. Hughes
Gene C. Hunder
Gunnar Husby
David Isenberg
J. Charles Jennette
Marcel-Francis Kahn

Edward C. Keystone

John H. Klippel

Joel Kremer

Nancy Lane

Ronald M. Laxer

Peter Lee

Peter E. Lipsky

Geoffrey O. Littlejohn

K. Wayne Marshall

Johanne Martel-Pelletier

Alphonse T. Masi

Gale A. McCarty

Henri Menard

Larry W. Moreland

Haralampos Moutsopoulos

Ola Nived

Akihide Ohta

Ignazio Olivieri

Gabriel S. Panayi

Richard Panush

Eliseo Pascual

Michelle Petri

Ross E. Petty

Theodore Pincus

Kenneth P.H. Pritzker

Angelo Ravelli

Naomi Rothfield

Anthony S. Russell

Philip N. Sambrook

Jorge Sanchez-Guerrero

H. Ralph Schumacher, Jr.

Alan J. Silman

Virginia D. Steen

Roger Sturrock

Eric M. Veys

Daniel J. Wallace

Michael Ward

Michael E. Weinblatt

Arthur Weinstein

Frederick Wolfe

Robert Wortmann

Yuqing Zhang

Robert B. Zurier
Recommendations for Use of Methotrexate in RA, studies on Vitamin D in SSc, a review on IgG4 Diseases, and Response to Adalimumab. In terms of overall viewing, full length articles are accessed the most, followed by editorials, reviews, and letter/case reports. 


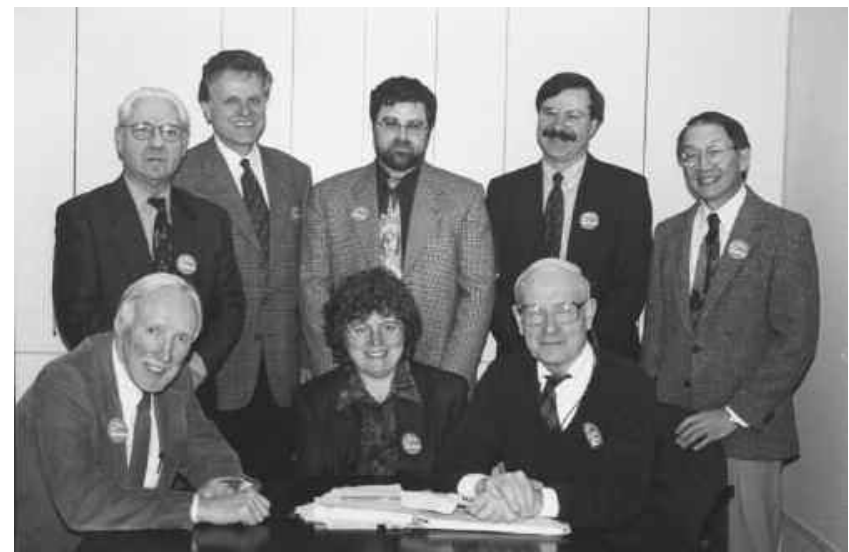

Figure 1. Editorial Committee.
All the above technical and organizational features are best when they support a vigorous medical research discovery cycle enhanced by our peer review system. Our thanks to all our contributors, whether authors, reviewers, editors, or subscribers, as The Journal embarks on our $38^{\text {th }}$ year of commitment to you. Moreover, your comments and concerns are always welcome.

YVONNE PIGOTT, Managing Editor; DUNCAN A. GORDON, MD, Editor 